\title{
The value of financial literacy and financial education for workers
}

\section{A financially literate workforce helps the economy, but acquiring the needed skills can be costly}

Keywords: financial literacy, education, saving

\section{ELEVATOR PITCH}

The level of financial literacy in developed countries is low and contributes to growing wealth inequality. Benefits from increasing the level of financial literacy include more effective saving for retirement and better debt management. However, there are significant costs in terms of time and money of acquiring financial literacy, which imply that the net value of acquiring financial literacy is heterogeneous in the population. This potentially makes designing effective interventions difficult.

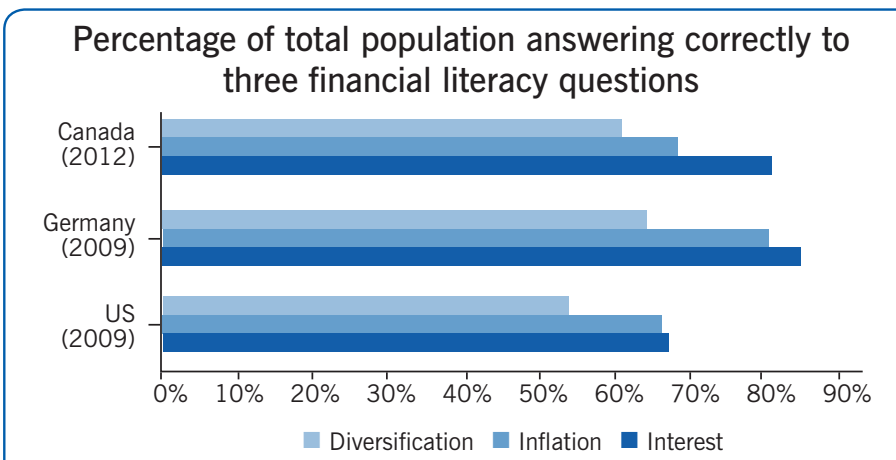

Source: [1], [2].

\section{KEY FINDINGS}

\section{Pros \\ ๑ Financial literacy is associated with better financial outcomes, such as more efficient saving and better debt management; in some cases the relationship is shown to be causal. \\ $\oplus$ Differences in financial literacy may amplify wealth inequality, so early interventions to provide financial literacy may reduce wealth inequality. \\ ( Financial education in schools has been shown to have positive effects on financial behaviors.}

\section{Cons}

- Delegating financial decisions to others could, in some circumstances, substitute for the need for higher financial literacy.

- Policy-driven behavioral interventions designed to "nudge" workers into taking certain actions may only raise well-being where workers are already financially literate; however, they may be better suited to address inaction and other behavioral biases that do not result from low financial literacy.

- Targeting those most in need of financial literacy may be difficult because the costs and benefits of financial knowledge are heterogeneous and thus "universal knowledge" may not be desirable.

\section{AUTHOR'S MAIN MESSAGE}

Evidence increasingly suggests an important role for financial literacy in shaping financial decisions and leading to wealth inequality. Recent evidence suggests that financial education could potentially have sizable effects in raising financial literacy, although studies have produced mixed results overall. While further research is certainly necessary, it appears obvious that the costs and benefits of financial literacy vary among different population groups. Policymakers should therefore focus on developing targeted education programs and not seek "universal knowledge" at all costs. 


\section{MOTIVATION}

Financial literacy is important for those interested in labor markets for at least three reasons. First, workers who lack basic financial literacy skills may be more likely to be financially distressed, with potential consequences for absenteeism and productivity. Second, they may have to work longer to reach the same level of retirement income because they failed to save for retirement or saved inefficiently via low-return products. Third, financially literate workers are more likely to understand a firm's financial situation, especially during economically challenging times, which may lead to better collective bargaining outcomes for all involved parties.

\section{DISCUSSION OF PROS AND CONS}

\section{Financial literacy and financial outcomes}

Financial literacy has been repeatedly found to be associated with better planning for retirement [3], higher net returns earned on savings [4], and holding of lower-interest debt [5]. This is a global phenomenon, with research showing a robust association between retirement planning, saving, and financial literacy around the world [1]. For example, a recent study using data from Canada shows that people who can correctly answer three financial questions-on interest compounding, diversification, and inflation-are ten percentage points more likely to plan for retirement than those who did not answer correctly (even after adjusting for many other individual-level characteristics) [2].

Nevertheless, it has been argued that this association might not be evidence of causality. To this end, many researchers have used instrumental variables analysis to correct for this possibility, and results remain statistically significant. For instance, a 2014 study argues that previous studies suffer from omitted variable bias, that is, that they do not control for all relevant factors [6]. Accordingly, the authors find that controlling for psychological traits, which were not accounted for in previous studies, diminishes the impact of financial literacy in explaining saving. Their four psychological traits are numeracy, propensity to plan for the use of money, confidence in information search, and willingness to take prudent investment risks. However, these factors could easily be a function of financial literacy, so it is unclear whether the study confirms that estimates are biased upward (i.e. they overestimate the real effect), or whether there is a more complex interaction between preferences, knowledge, and behavior that must be further examined.

Even if causality may run both ways and unobserved traits may impact the relationship in both directions, this statistically and economically meaningful association deserves attention. This is because consumers have access to an ever-growing basket of financial products and the freedom to make choices that they could not make in the past. While this is mostly good news, it also presents consumers with more complex and potentially dangerous new options. This means that consumers lacking skills to make savvy financial choices may end up failing to reach their goals, leaving governments or employers to pick up the bill. Accordingly, the consequences of financial illiteracy are many, and understanding the process by which some consumers do better than others at saving, borrowing, and preparing for retirement is an important undertaking. 


\section{Delegation and nudges}

One solution proposed to address widespread financial illiteracy is to have people delegate their financial decisions to other agents. In the past, for instance, governments have often made "intermediated" saving decisions for the population in a wide range of domains, including by requiring mandatory public pensions. In many countries, mandatory occupational or company-based pensions remain in place, where workers must remain with a firm for an entire career if they are to reap the retirement pension reward. One downside to mandatory participation in defined benefit schemes is that workers with shorter-than-average life expectancies, such as coal miners or farmers, receive lower returns on their contributions than, for example, lawyers or university professors do.

In recent times, labor and financial market changes have reduced governments' and employers' capacity to retain the intermediated saving model. Labor market mobility is on the rise, and workers have very different personal circumstances than previous generations did. As a consequence, the decision of how much to save for retirement is a complex one, and optimality requires tailor-made saving plans. While taking responsibility for their own saving can be welfare-improving when employees are well-equipped to make good decisions [7], those truly unwilling to make their own decisions can still delegate saving and investment choices to financial advisors. Yet potential conflicts of interest between the advisor and the worker imply that delegation cannot perfectly substitute for financial literacy. A study from 2012 offers a cautionary tale, finding that financial advisors reinforced clients' biases and pushed for managed funds with higher fees, resulting in worse outcomes for the clients [8].

Other authors have proposed that so-called "behavioral framing"-or "nudge" interventions-can help overcome financial illiteracy [9]. These interventions have been shown to be effective at solving well-known problems such as present bias (i.e. overstating of present and understating of future outcomes) or procrastination (i.e. delaying important decisions) [10]. For example, automatically enrolling workers into a retirement savings plan strongly increases savings, and although workers are allowed to opt out if they wish, evidence suggests that few do. The province of Quebec in Canada recently introduced a savings program that required employers who did not offer a pension plan to offer a voluntary savings program which defaulted savers into a Registered Retirement Savings Plan (RRSP) akin to the US 401(k) plan. Although a program such as this is likely to raise participants' savings (because many are passive savers), questions nevertheless remain as to whether this enhances overall welfare. This uncertainty arises because saving more is not necessarily optimal for all individuals, and the best investment portfolio is likely to vary across workers. Moreover, saving may not be adequate or high enough to guarantee a secure retirement, as contributions are usually set at a low rate, typically around $3 \%$.

What makes nudging (in the form of auto-enrollment) potentially superior to mandatory choices is the possibility that workers can overcome behavioral biases while still making a choice that is optimal. Workers for whom the default is not optimal should understand that they should opt out. However, as is the case with mandatory savings programs, when workers are financially illiterate, the burden of making the "right" choices rests with those who designed the choice architecture. In fact, Quebec's default RRSP (401k) option can be undesirable for low earners who will receive close to full income replacement in retirement and face up to $75 \%$ effective tax rate on any new pension income from 
the savings program. Hence, behavioral intervention aimed at raising savings is, while effective, only superior to mandatory programs when workers are financially literate and therefore have the possibility to make informed choices.

\section{What is the right level of financial literacy?}

Since investing in financial literacy is costly, it is arguably not optimal for everyone to know about advanced concepts such as stocks, bonds, and basic asset pricing, just as it is not optimal for every high school physics teacher to understand the latest developments in quantum physics. Accordingly, there is an important question with regard to determining the optimal level of worker financial knowledge, in what domains, and at what age. For some elements of financial literacy, the task of figuring out the optimal level is easy. Understanding the "Big Three" questions covering compound interest, inflation, and risk diversification, are life skills which, in today's world, are as important as it was 50 years ago to know how to sew or hit a nail. But is learning about reverse mortgages or the difference between exchange-traded-funds and mutual funds important for all workers at any age?

This question has been investigated in terms of optimality in a life cycle model with uncertainty in labor earnings, out-of-pocket medical expenditures, and returns on financial products [9]. It was assumed that workers would wish to invest in financial literacy because this raises the expected rate of return on more sophisticated financial products such as stocks, due to their picking better stocks or saving on fees. However, investing in financial literacy is costly in terms of both time and money. In a human capital framework, workers will seek to invest in financial literacy up to the point where the marginal return (in terms of additional wealth due to better returns and higher lifetime consumption) equals the marginal cost. Financial literacy also depreciates over time, which adds to the cost of holding more financial knowledge. The developed model was used to generate optimal paths of financial knowledge by education level. In Figure 1, under very general conditions, the optimal path of financial knowledge is shown to be hump-shaped, increasing first as households start to save and thus benefit from higher returns, and then declining once workers start spending their savings. Despite allowing for differences by education in earnings, longevity, and health risks, the findings show that workers with higher education consistently invest more in financial knowledge. This results from their need to save more for retirement than the lower-paid, because pensions tend to replace less of their earnings in retirement (as, for example, social security replacement rates decrease as income increases).

\section{Wealth inequality}

When better-educated workers have greater incentives to accumulate financial knowledge, and financial knowledge increases returns on savings, this gives rise to the potential for endogeneous financial knowledge to generate inequality in wealth (and lifetime consumption). The potential for this situation is shown to be large and robust to a number of assumptions for parameter values of the life cycle model [7]. Figure 2 reports the ratio of simulated wealth at retirement, comparing those with college education to high school dropouts. In the figure, average wealth is expressed as a multiple of average lifetime income. Under the standard life cycle model, that ratio should be one. The 
Figure 1. Simulated path of optimal financial knowledge and expenditures by education and age
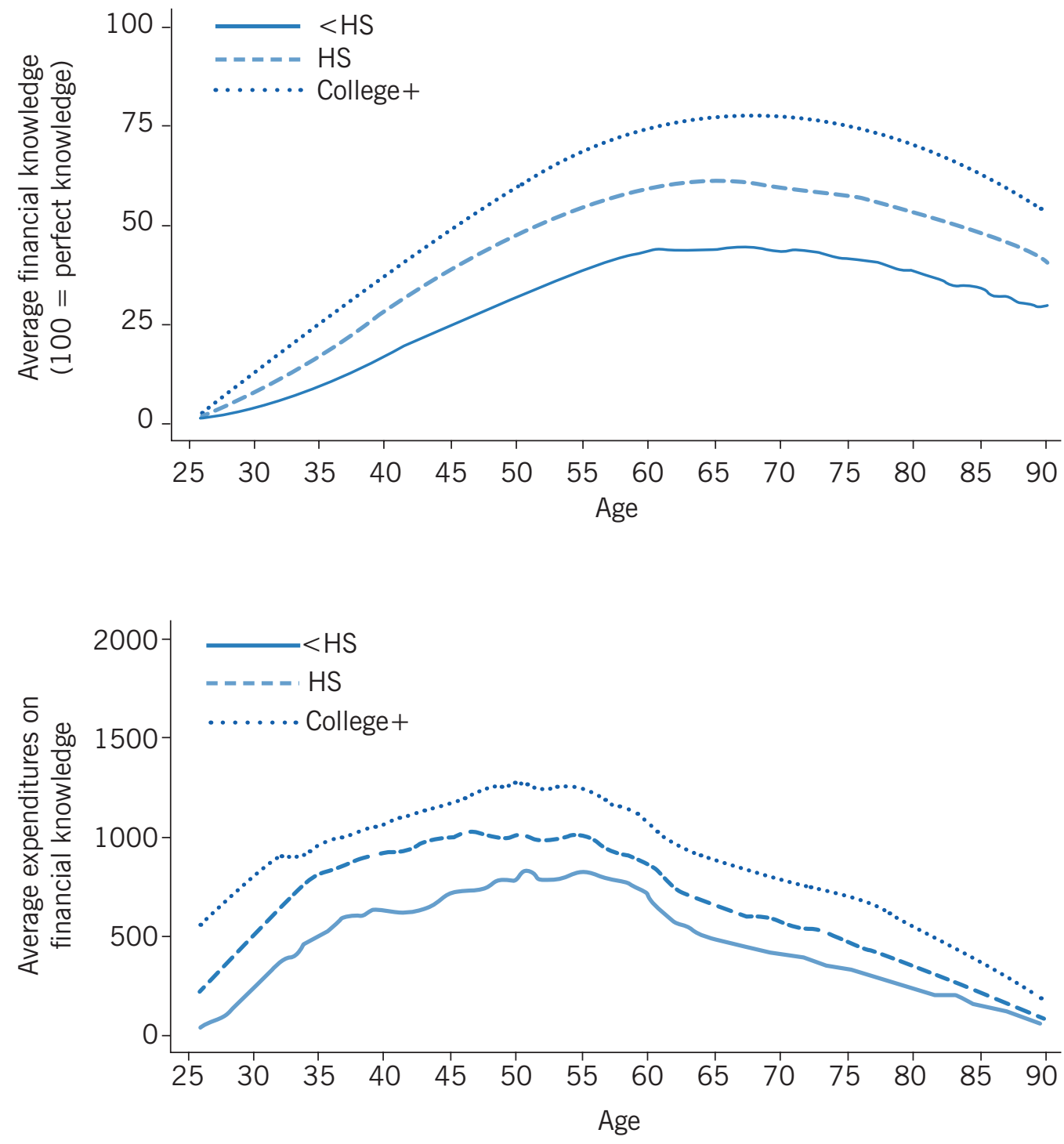

Note: $<\mathrm{HS}=$ less than high school; $\mathrm{HS}=$ high school completed; College $+=$ some college education.

Source: Lusardi, A., P.-C. Michaud, and O. S. Mitchell. "Optimal financial knowledge and wealth inequality." Journal of Political Economy 125:2 (2017): 431-477 [7].

model for high earners is a scaled up version of the model for the poor. As heterogeneity exists in various components of the choice environment (e.g. earnings, longevity, family composition, or medical risk), inequality increases above one but never approaches the levels observed in the data. However, once the model allows workers to invest in financial knowledge endogenously (e.g. acquire knowledge, follow a class, or purchase software), inequality increases substantially and the results match the data relatively well. Financial literacy is thus found to matter a great deal, and can in fact account for more than onethird of wealth inequality for those close to retirement. 
Figure 2. Simulated wealth ratio (college/less than high school) across households with different education levels

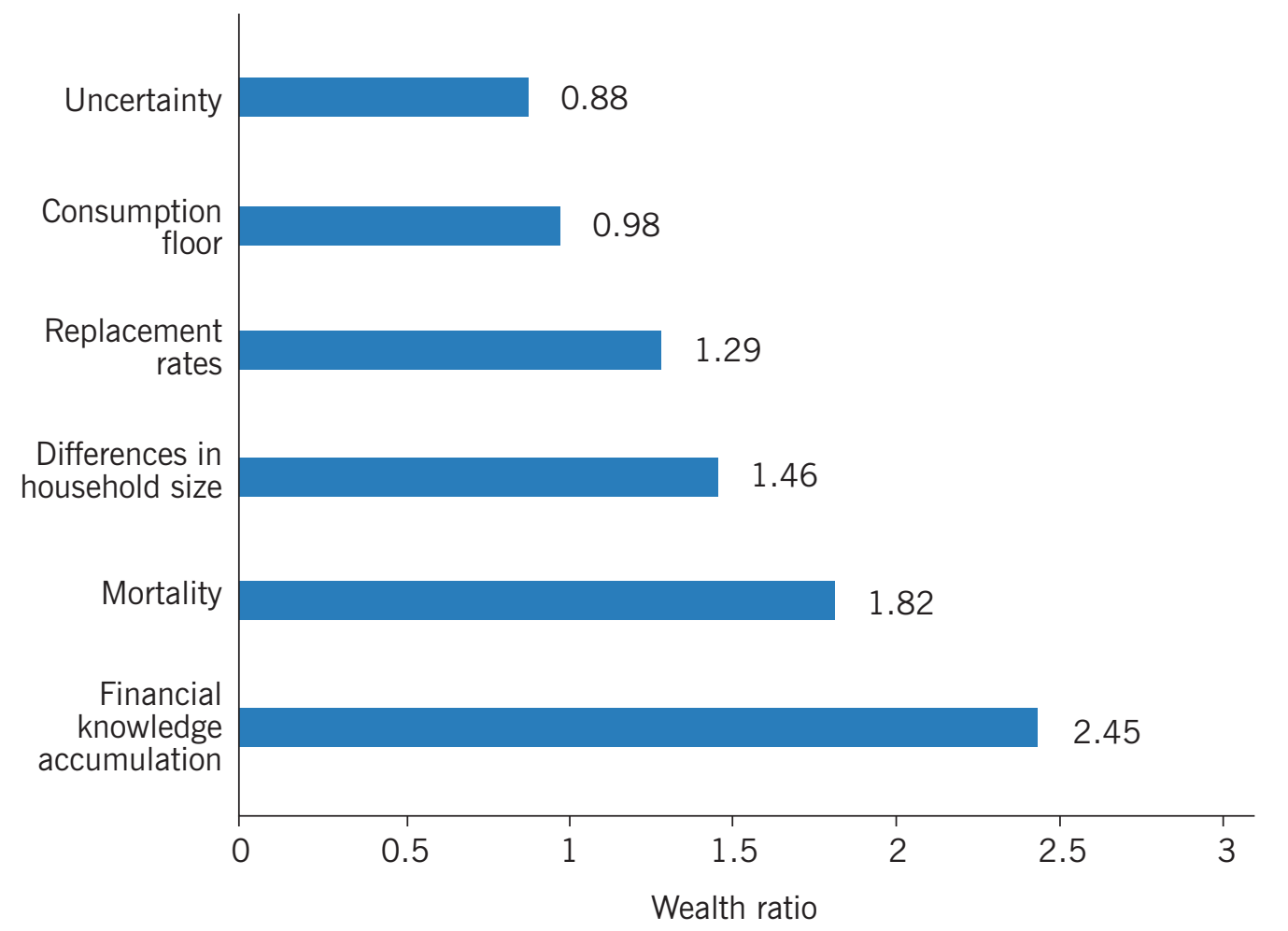

Note: For each simulation, the ratio of average wealth at retirement for those with a college degree and those with less than a high school degree is reported. A ratio of one implies that after accounting for differences in average lifetime income, those with a college degree have accumulated the same level of wealth as those with less than a high school degree.

Source: Lusardi, A., P.-C. Michaud, and O. S. Mitchell. "Optimal financial knowledge and wealth inequality." Journal of Political Economy 125:2 (2017): 431-477 [7].

\section{Effectiveness of financial education}

Skills are acquired by education and experience, and many (though not all) educational programs have been shown to be effective at teaching new skills. Similarly, the question is not whether financial literacy is useful or effective, but whether financial education is cost-effective at increasing financial literacy for those with too little of it. Answering this question requires one to think carefully about the evaluation, targeting, and design of such programs.

As with any policy question, establishing causality is crucial. If experience drives improvements in financial literacy, for example via learning-by-doing, then providing workers with financial education may do little to raise financial literacy. Instead, one might advise workers to invest in stocks so they eventually learn about diversification and compound interest. This is an implausible approach, however, since so many people cannot answer the Big Three questions, including many with investment experience. Conversely, when financial literacy leads to better financial outcomes, the policy prescription would be to provide cost-effective financial education. While some reviews offered mixed evidence of program effectiveness [6], the most recent literature provides clearer evidence in favor of financial literacy training [11]. 


\section{A simple measure of financial literacy: The "Big Three" questions}

The following three questions are often used to measure financial literacy (Lusardi and Mitchell, 2011). Correct answers are indicated with two asterisks.

(i) Suppose you had $\$ 100$ in a savings account and the interest rate was $2 \%$ per year. After five years, how much do you think you would have in the account if you left the money to grow?

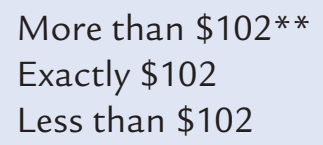

(ii) Imagine that the interest rate on your savings account was $1 \%$ per year and inflation was $2 \%$ per year. After one year, how much would you be able to buy with the money in this account?

More than today
Exactly the same
Less than today**

(iii) Please tell me whether this statement is true or false: "Buying a single company's stock usually provides a safer return than a stock mutual fund."

True

False**

Source: Lusardi, A., and O. S. Mitchell. "Financial literacy around the world: An overview." Journal of Pension Economics and Finance 10:4 (2011): 497-508.

There are two natural and scalable settings for offering financial education: in schools and at the workplace. There is some evidence that financial education in school has important effects on a wide range of outcomes, including both savings and debt [12]. The effects of workplace financial education are harder to assess. One reason is that participation in workplace programs tends to be voluntary. Depending on how selection into these programs works, simple participant vs non-participant comparisons are misleading.

A study from 2015 [13] explores the question of evaluation within the context of the life cycle model developed in [7]. The authors create an experiment within the context of the model that allows agents to choose whether to participate in a financial education program that would raise their financial knowledge exogeneously, but which costs $\$ 500$. Crucially, the offer to participate in the program is randomized across simulated agents. In this model, participants are those who expect to benefit most from the program, in other words, those with current financial knowledge below what they would consider as the optimal stock of financial knowledge at that age.

Figure 3 shows the life cycle pattern of investment in knowledge, stock of financial knowledge, change in wealth, and share of wealth invested in sophisticated financial products (e.g. stocks). With this simple exercise, a number of important problems about evaluation arise when participation is voluntary. First, it is not optimal for everyone to participate, so a lack of participation should not necessarily be considered a negative outcome. Second, those who participate are clearly workers with higher saving rates who engage with sophisticated financial products more frequently or to a higher degree. 
In addition, the age profiles between participants and non-participants differ. Hence, a simple difference-in-differences analysis is not possible without controlling for differences in trends. Third, the program's effect on participants' financial knowledge is short-lived for smaller and shorter-term interventions: although participants invest more money as a result of the program, they lower their investment activities relative to the counterfactual (in which they did not participate) until they reach the same optimal stock of financial knowledge whether or not they participated. Although there are no long-term effects, the welfare effects of being able to invest in financial knowledge at a lower cost mean higher consumption over participants' lifetimes. Hence, it is possible to obtain no long-term effects on wealth, but to still reap substantial welfare benefits from the program [13].

Figure 3. Effects of a financial education program over the life cycle
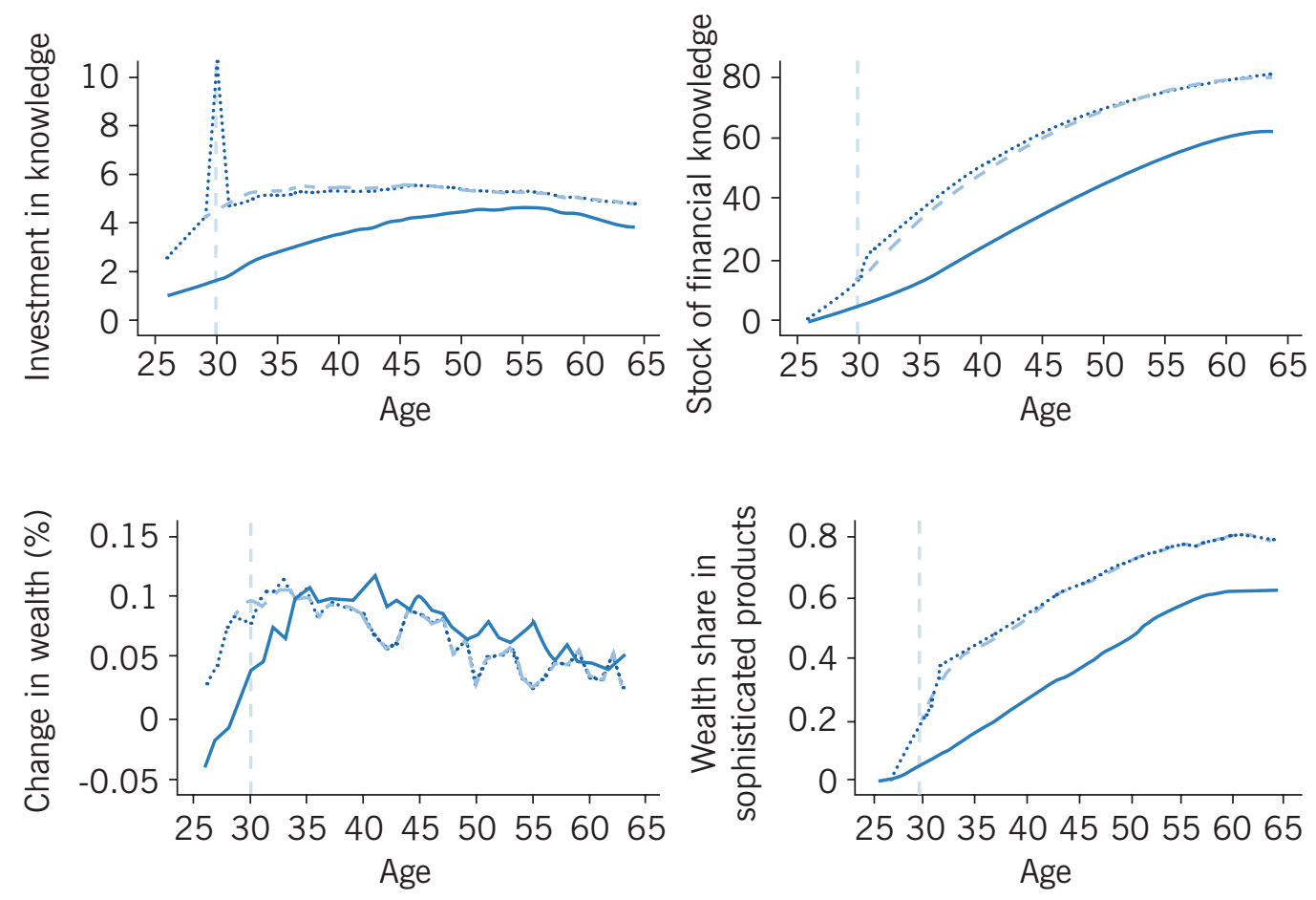

Not enrolled

Enrolled

Enrolled (counterfactual)

Note: For participants, the counterfactual age profile, had they not participated in the program, is also plotted. Intervention is at the age of 30 , with a program cost of $\$ 500$ and relative marginal cost of 0.5.

Source: Lusardi, A., P.-C. Michaud, and O. S. Mitchell. Using a Life-Cycle Model to Evaluate Financial Literacy Program Effectiveness. TIAA-CREF Institute Research Dialogue No. 122, November 2015 [13].

Given this complex situation, how should such programs be evaluated? The 2015 study shows that simple ordinary least squares estimates of the long-term effects on wealth accumulation are substantially upward biased. The fact that the program was offered on a randomized basis is then used to obtain estimates that are close to zero for smaller programs and sizable as the programs become more effective [13]. This shows that randomization is important in order to obtain unbiased estimates of the programs' effects. To estimate effects on welfare, information about expenditures or direct measurement of well-being may be needed, especially for smaller interventions where long-term effects 
on wealth accumulation may not be visible. Given that optimal participation is not universal, it is important to target those most in need of financial education. As the model presented in [13] makes clear, one needs to know the entire earnings trajectory, amongst other characteristics, of the households to make an assessment of need for retirement saving education. It is not just about identifying high and low earners. For example, if policymakers are interested in providing education on the trade-offs between pre-tax and tax-deferred saving products in Canada, the target group is not poor working individuals, who probably do not want to save in the first place. Instead, the target group would likely be middle earners or earners who temporarily have high earnings, who may be at risk of facing very high effective marginal tax rates in retirement. That level of targeting is harder to accomplish, but not impossible.

\section{LIMITATION AND GAPS}

While researchers are gaining a better understanding of how to conceptualize the accumulation of financial knowledge over the life cycle and how to evaluate interventions, there are a number of important research gaps that need to be filled. First, more work is needed in understanding other dimensions of financial knowledge investment. In particular, there are questions around how financial knowledge might allow one to manage debt more effectively and responsibly, and to make insurance decisions throughout life, particularly during old age (e.g. purchasing annuities, long-term care insurance, and engaging in a reverse mortgage). Second, more randomized controlled experiments are necessary to evaluate what works for whom when it comes to financial education in schools or the workplace. Employers should work closely with researchers to design interventions that can be evaluated using appropriate methods. Third, understanding the connection between cognitive decline and financial knowledge will likely be important in the future, as more retirees and near-retirees make difficult decisions about deccumulating wealth in defined contribution plans (plans where retirees need to plan withdrawals rather than receive a steady benefit). The vulnerability of retirees and near-retirees, in part because of cognitive decline, may present important challenges for policymakers and other stakeholders. As more countries continue to undertake and implement financial education programs and researchers gain more data, there is a lot left to learn about the importance of financial literacy.

\section{SUMMARY AND POLICY ADVICE}

Over the last 20 years, a large body of research has shown that the level of financial literacy across many countries is relatively low and that higher financial literacy is associated with better financial outcomes. Financial literacy also plays an important role in increasing wealth inequality, and recent evidence on the impact of financial education points to positive effects. The need for financial education varies in the population as there are heterogeneous benefits and costs associated with knowledge acquisition. Hence, policymakers should not aim for universally high levels of financial literacy without weighing the costs and benefits for specific socio-economic groups. Nor should they see behavioral interventions, such as defaults, as pure substitutes for financial literacy. These interventions may work well to address behavioral biases, but will only guarantee welfare enhancing outcomes in a world where workers are financially literate. Policymakers should encourage the development of targeted education programs and devote considerable 
attention to the evaluation of such programs using state-of-the-art evaluation methods such as randomized controlled experiments. Profound changes to labor and financial markets present a new set of challenges for workers, marked in particular by increased financial responsibility. Policymakers should respond to these challenges by paying close attention to the capability of individuals to make complex financial decisions and by providing easy access to educational opportunities.

\section{Acknowledgments}

The author thanks an anonymous referee and the IZA World of Labor editors for many helpful suggestions on earlier drafts. Previous work of the author contains a larger number of background references for the material presented here and has been used intensively in all major parts of this article [7], [13]. The author acknowledges comments and suggestions from David Boisclair, Olivia Mitchell, and Annamaria Lusardi. Some of the work reviewed was done in collaboration with Annamaria Lusardi and Olivia Mitchell. Part of this work has been financed by NETSPAR, the Pension Research Council and Boettner Center for Retirement Research at the Wharton School of the University of Pennsylvania, the RAND Corporation, and the Fonds de Recherche du Québec-Société et culture .

\section{Competing interest}

The IZA World of Labor project is committed to the IZA Guiding Principles of Research Integrity. The author declares to have observed these principles.

(c) Pierre-Carl Michaud 


\section{REFERENCES}

\section{Further reading}

Bernheim, B. D., D. M. Garrett, and D. M. Maki. "Education and saving: The long-term effects of financial curriculum mandates." Journal of Public Economics 80:3 (2001): 435-465.

Madrian, B. C., and D. F. Shea. "The power of suggestion: Inertia in 401(k) participation and savings behavior." The Quarterly Journal of Economics 116:4 (2001): 1149-1187.

\section{Key references}

[1] Lusardi, A., and O. S. Mitchell. "Financial literacy around the world: An overview." Journal of Pension Economics and Finance 10:4 (2011): 497-508.

[2] Boisclair, D., A. Lusardi, and P.-C. Michaud. "Financial literacy and retirement planning in Canada." Journal of Pension Economics and Finance 16:3 (2017): 277-296.

[3] Lusardi, A., and O. S. Mitchell. "The economic importance of financial literacy: Theory and evidence." Journal of Economic Literature 52:1 (2014): 5-44.

[4] Clark, R., A. Lusardi, and O. S. Mitchell. "Employee financial literacy and retirement plan behavior: A case study." Economic Inquiry 55:1 (2017): 248-259.

[5] Huston, S. J. "Financial literacy and the cost of borrowing." International Journal of Consumer Studies 36:5 (2012): 566-572.

[6] Fernandes, D., J. G. Lynch Jr., and R. G. Netemeyer. "Financial literacy, financial education, and downstream financial behaviors." Management Science 60:8 (2014): 1861-1883.

[7] Lusardi, A., P.-C. Michaud, and O. S. Mitchell. "Optimal financial knowledge and wealth inequality." Journal of Political Economy 125:2 (2017): 431-477.

[8] Mullainathan, S., M. Noeth, and A. Schoar. The Market for Financial Advice: An Audit Study. NBER Working Paper No. 17929, March 2012.

[9] Thaler, R. H., and C. R. Sunstein. Nudge: Improving Decisions About Health, Wealth, and Happiness. Updated edition. London, UK: Penguin Books, 2009.

[10] Madrian, B. C. "Applying insights from behavioral economics to policy design." Annual Review of Economics 6 (2014): 663-688.

[11] Kaiser, T., and L. Menkhoff. Does Financial Education Impact Financial Literacy and Financial Behavior, and IfSo, When? DIW Berlin Discussion Paper No. 1562, May 2017.

[12] Brown, M., J. Grigsby, W. van der Klaauw, J. Wen, and B. Zafar. "Financial education and the debt behavior of the young." The Review of Financial Studies 29:9 (2016): 2490-2522.

[13] Lusardi, A., P.-C. Michaud, and O. S. Mitchell. Using a Life-Cycle Model to Evaluate Financial Literacy Program Effectiveness. TIAA-CREF Institute Research Dialogue No. 122, November 2015.

\section{Online extras}

The full reference list for this article is available from:

http://wol.iza.org/articles/the-value-of-financial-literacy-and-financial-education-for-workers

View the evidence map for this article:

http://wol.iza.org/articles/the-value-of-financial-literacy-and-financial-education-for-workers/map 